\title{
Study on the Ideological and Political Education Work System based on WEB Technology
}

\author{
Yang DONG \\ Chongqing Medical and Pharmaceutical College \\ Chongqing, China
}

\begin{abstract}
According to the content and characteristics of Ideological and political education website, this paper designs a the network education platform with teacher-student interaction, psychological counseling, student self-display and other functions based on Web development technology of .NET, using ASP.NET and C\# to realize each functional module of Ideological and political education system; at the same time, we studied the Web services and encryption technology based on WEB, and proposed a campus information exchange and implementation of single login on system model. Using functional analysis method to establish the demand model of the system, combined with the actual situation of the relevant theory of the database, design the conceptual structure and logical structure for system database. The paper design the system implementation process and the specific implementation strategy, network ideological and political education platform provides some reference and inspiration for the university.
\end{abstract}

Keywords-Mathematics; Ideological and political education; web technology; Asp.net; Security technology;

\section{INTRODUCTION}

With the rapid development of Internet, the network has become an important part of university staff and students to study, work and life, but also to the traditional mode of Ideological and political education has brought great challenges. The University launched a variety of useful attempts in the ideological and political education in network, the rise of the ideological and political education website construction boom, all kinds of educational websites such as bamboo shoots after a spring rain as vigorous development. Also attracted attention from the Institute for leadership, proposes to establish a suitable College Ideological and political education website.

This paper studies the object of Ideological and political education website that is a sub-site in campus network, as a sub-site, it not only have its own theme style, unified login, the user also can solve the interoperability problem of campus information.

\section{ANALYSIS OF THE CAMPUS NETWORK SYSTEM}

Ideological and political network is as a sub-web of campus network system, modules are independent of the network system of the campus, but also it can communicate with other subsystem in campus network. In the survey, the biggest problems of campus network system is the campus user login and news and other information is not uniform, considering the construction of campus network unified platform in the future, the ideological and political website is necessary to set up the two interface. Figure 1 is the basic structure of the campus network diagram.

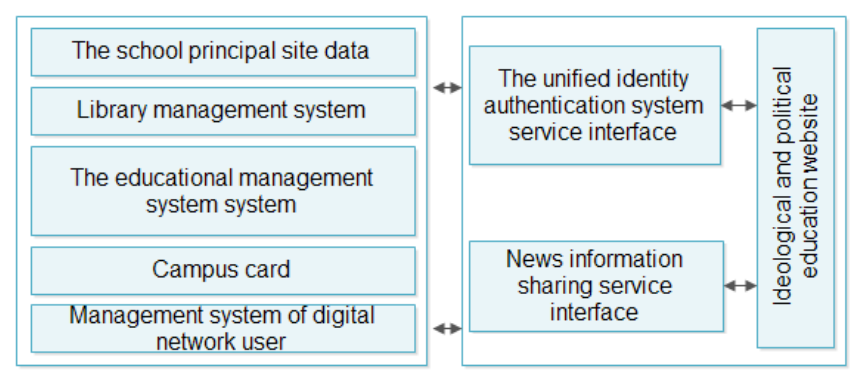

Fig.1 The basic structure of campus network

According to the function analysis of the system in Figure 1, the author designed the function module of College Ideological and political network system based on VOD, which is composed of video on demand module, management module, interface module, a recording module. As shown in figure 2. Among them, the video module realize video on demand, video content guide, video indexing function; management module realize function of upload, modify, delete, add, modify, delete column video resources and forum management; online interaction module realize function of learning forum and other functions; recording module through a personal learning portfolio form, the realization of students' basic information display, function learning experience process record, published topics and posts, upload etc..

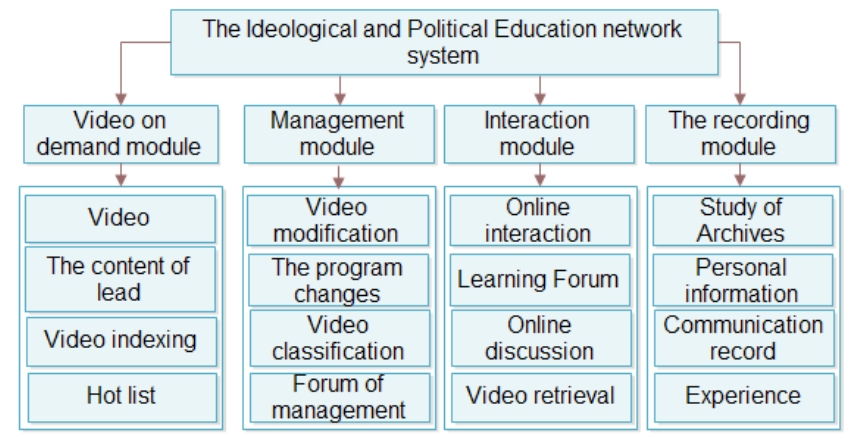

Fig.2 Module structure of Ideological and political education subsystem 


\section{THE STRUCTURAL DESIGN OF IDEOLOGICAL AND POLITICAL EDUCATION SYSTEM}

The structure of the system mainly includes two aspects of foreground and background, foreground is the main variety of presentation of information, which mainly includes: in the background of information release, management.

First of all, we will install system on the server, the video resources are uploaded to the server through the background, and through the background management of all kinds of information.

Secondly, in the network, by entering the URL in a browser, through the system front display, you can see the upload video content is very convenient.

Finally, a video web site also need to set at the server site. Only get a domain name and space and configured, in order to see the video web site in the front display through the web site.

The site consists of foreground and background components, as shown in figure 3 . The prospects of using div + css layout, constituted by calling the.Net platform components. The background of the operation of the database by using the $\mathrm{C \#}$ language, and establish with the front connection makes data are shown in the foreground, database using ACCESS database design. The overall structure of the system is as shown in figure 3 .

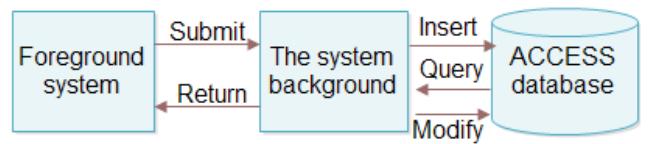

Fig.3 The overall structure of the system

In the system, the user behavior is oriented Web server, system management is realized through the efficient access to the ACCESSS database. Specific process is as follows: the user through a browser directly enter the URL to open the system, obtain to obtain information, at the same time in submission page through the realization of the data submitted by the code. For the background is the administrator of the data add, delete and modify etc.. In the process of adding, on video, the user information, such as a series of content to add the use of components. In the modification process, to obtain the data in the database and the data modification, finally it is stored in the database.

\section{A. Design of the background system}

The background of the system is mainly to complete the video management, forum management, user management tasks. The backstage function structure chart of the system is shown in figure 4 .

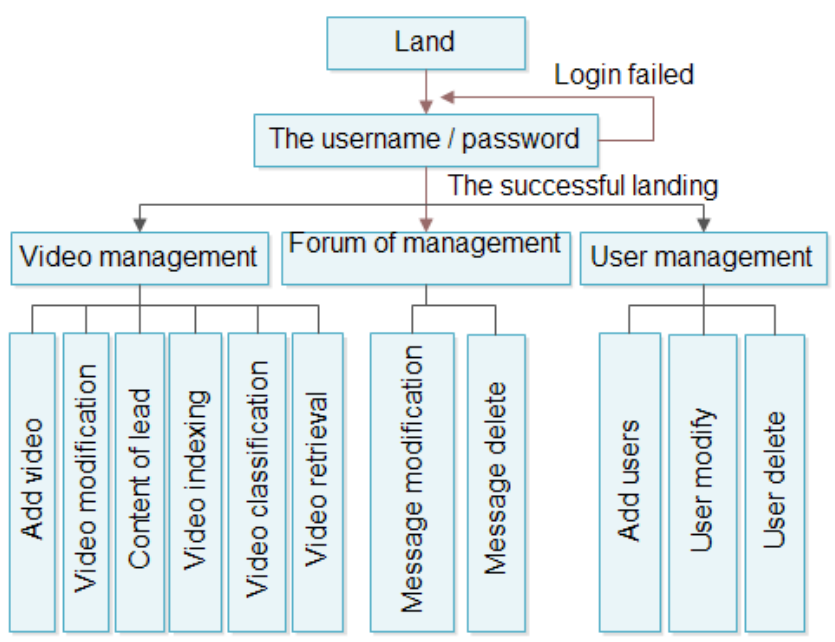

Fig.4 The function structure of background system

\section{B.The design of foreground}

Foreground system includes display, information exchange information, information recording and submission of reflective reporting function. The function structure chart of the foreground system is shown in figure 5.

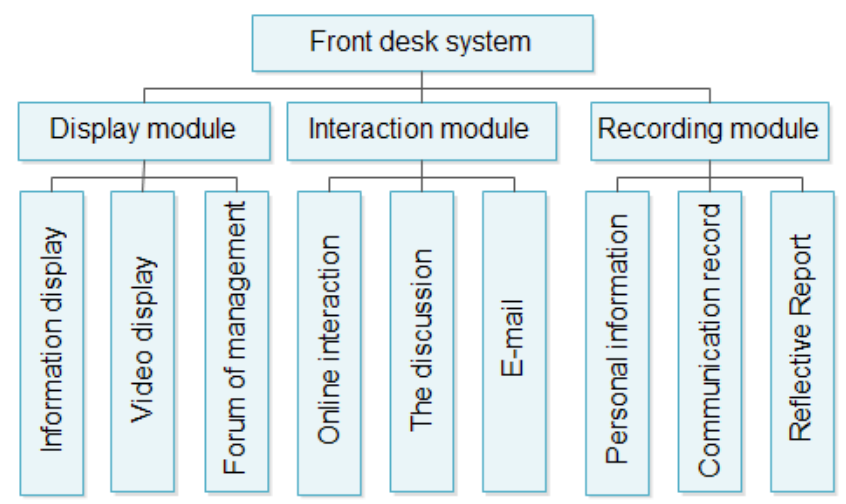

Fig.5 The function structure chart of the foreground system

In the foreground video site, the main use for database queries, to realize the database content foreground display.

\section{THE DESIGN AND IMPLEMENTATION OF KEY FUNCTIONS}

\section{A. addition and modification of video}

The video format is into FLV format in upload process, call ffmpeg and mencoder video program to convert, setting different parameters will be to realize the conversion of video, GridView will read, modify, delete the video operation in the uploading process for reading video. The uploading process, GridView read the video information using GridView component.

In the video management module, in order to realize the conversion of video, to realize the transformation function of video by using the following code: 
$<$ <appSettings>

$<$ add

key="ConnectionString"

value $="$ Provider=Microsoft. Jet. OLEDB. 4. 0; Data Source=!

DataDirectory, managers.mdb"/>

$<$ ! 一 Tools folder $\rightarrow>$

<add key="ffmpeg" value $=$ "=/ffmpeg/ffmpeg.exe"/>

<add key="ffplay" value="=/ffmpeg/ffplay.exe"/>

$<$ add key $="$ mencoder" value $="=/$ mencoder

/mencoder.exe"/>

$<$ ! - Path to uploaded files $\rightarrow>$

<add key="upfile" value="=/UpFiles"/>

$<$ ! - Path to uploaded picture $\rightarrow>$

$<$ add key="imgfile" value="=/ImgFile"/>

$<$ !一 Upload file size of images $\rightarrow$

$<$ add key="CatchFlvImgSize" value="240x180"/>

$<$ add kev="widthSize" value $=" 400 " />$

$<$ add key="heightSize" value="350"/>

$<$ ! - the file path after converting $\rightarrow$

$<$ add key="playfile" value="=/PlayFiles"/>

$</$ appSettings>

Video conversion calls the publicmothed class. In the transformation, achieve video call PublicMethod.cs to realize the storage class video information, transforming this kind of realization of video, the video avi format turn into FLV format, that is convenient video playback. The code below:

string playFile=Server.MapPath(PublicMethod.playFile+ saveName);

string imgFile=Server.MapPath(PublicMethod.imgFile+ saveName);

PublicMethod pm=new PublicMethod();

String $\mathrm{m}$ strExtension= Publ icMethod. GetExtension (this. FileUploadl. PostedFi 1e. Fi leName).ToLower();

\section{B. Forum management}

For the information submitted to the management managed by the background. Administrator login background management system, management for the message content to prevent the spread of harmful information etc.. Forum for the management, mainly using the background query to retrieve the keywords, to achieve control of the harmful information. In the technical aspects of the main is to use the SQL statement, defined by different conditions to realize the query etc..

The query code as follows:

string sql="select id,content,beyond,adder,timeadd from liuyan where content $=$ '“+ + content + "'”'

Users watch video by the front desk, at the same time the user can facilitate exchange between users through the message way. The content is mainly through the use of session to get the user name and password to achieve, it is using session to realize whether the user login.

Session verification code is as follows:

Session["users"]="”

Session["userpwd"]=“"”;

Response. Redirect ("'index. aspx");

\section{Structure design of database system}

This system uses Microsoft Access database, use multiple data tables to save the data. Among them, the Vod table is used to store video ID, video title, video chat, video category, video content, video address, add people, adding time, hit number and other information. It was shown in Table 1.

Table.1 User table

\begin{tabular}{|c|c|c|c|c|}
\hline List & Type & Length & Null & Description \\
\hline ID & auto & Long int & $\mathrm{N}$ & Only \\
\hline UserName & Text & 50 & $\mathrm{~N}$ & Name \\
\hline UserPwd & Text & 50 & $\mathrm{~N}$ & Password \\
\hline Name & Text & 16 & $\mathrm{~N}$ & Name \\
\hline Xueli & Text & 8 & $\mathrm{~N}$ & Education \\
\hline Byxx & Text & 50 & $\mathrm{~N}$ & School \\
\hline Lianxi & Text & 50 & $\mathrm{Y}$ & contact \\
\hline Csrq & Text & 50 & $\mathrm{Y}$ & date \\
\hline Email & Text & 50 & $\mathrm{Y}$ & email \\
\hline Jianli & Text & Note & $\mathrm{N}$ & Resume \\
\hline Adder & Text & 50 & $\mathrm{Y}$ & Add \\
\hline Author & Text & 4 & $\mathrm{~N}$ & authority \\
\hline Addtime & Time/Date & Time/Date & $\mathrm{N}$ & Add time \\
\hline
\end{tabular}

Table.2 Discuss table

\begin{tabular}{|l|l|l|l|l|}
\hline List & Type & Length & Null & Description \\
\hline ID & Auto & LongInt & $\mathrm{N}$ & Only \\
\hline UserName & text & 50 & $\mathrm{~N}$ & Name \\
\hline Xingming & text & 255 & $\mathrm{~N}$ & Real name \\
\hline Zhuti & text & 2 & $\mathrm{~N}$ & Topic \\
\hline Neirong & text & 255 & $\mathrm{Y}$ & Content \\
\hline Addtime & text & 255 & $\mathrm{~N}$ & SubjectTime \\
\hline
\end{tabular}

Table.3 Video table

\begin{tabular}{|l|l|l|l|l|}
\hline List & Type & Length & Null & Description \\
\hline ID & auto & Long int & $\mathrm{N}$ & Only \\
\hline Vodtitle & text & 50 & $\mathrm{~N}$ & Video topic \\
\hline Vodaddr & text & 255 & $\mathrm{~N}$ & $\begin{array}{l}\text { Video } \\
\text { address }\end{array}$ \\
\hline Vodbeyond & text & 2 & $\mathrm{~N}$ & Videi type \\
\hline Vodcontent & text & 255 & $\mathrm{Y}$ & $\begin{array}{l}\text { Video } \\
\text { content }\end{array}$ \\
\hline Pieaddr & text & 255 & $\mathrm{~N}$ & $\begin{array}{l}\text { Video } \\
\text { Screenshot }\end{array}$ \\
\hline Useadder & text & 20 & $\mathrm{Y}$ & Add user \\
\hline Addtime & Date/Time & Date/Time & $\mathrm{N}$ & Add time \\
\hline
\end{tabular}

\section{CONCLUSIONS}

The paper constructs the function structure chart of College Ideological and political education network system based on VOD, and develop Ideological and political 
education and network system based on video on demand, the University Ideological and political education network system will apply to specific educational practice based on video on demand, and makes an analysis on the result. In the course of the study, on the basis of comprehensive analysis, designs the implementation process of the system and the specific implementation strategies, and provides some reference and inspiration for the universities to improve the effect of network ideological and political education.

\section{ACKNOWLEDGEMENTS}

special subject of Students' Ideological and political education in the Chongqing City Board of education, Project No. 13 skszr04

\section{REFERENCE}

[1] Li Haiyan, Guo Cheng. Analysis of Chinese and foreign network education development present situation [J].

[2] Chinese adult education, 2007.8: 119-120

[3] Wang Gang. Use the university website to strengthen ideological and political education of College Students [J]. Journal of Daxian Teachers College, 2006.6:11-13

[4] Yan Hua. Study on the ideological and political education of College Students under the network environment [D]. Hunan University, 2004.5

[5] Liu Zhihong, Zhou Zhenjun. Analysis and application of the teaching and VOD system based on campus network [J]. Teaching and management, 2009, (1): 25-26

[6] Ma Qiaohuan. The design and function of VOD video on demand system based on Web [J]. Mining and metallurgy, 2006, (15): 100102. 